\title{
Bissu: Keistimewaan Gender dalam Tradisi Bugis
}

\author{
Titiek Suliyati \\ Program Studi Sejarah Fakultas Ilmu Budaya dan Diploma III Kearsipan Sekolah Vokasi, \\ Universitas Diponegoro Semarang \\ Email: suliyati.titiek@gmail.com
}

\begin{abstract}
As one of many ethnics in Indonesian, Bugis ethnic posses much uniqness compared to other Indonesian ethnics. Bissu as one of Bugis traditions is gender spisification that does not exist either in man or woman. Indonesian society generally acknowledge man and woman gender. This is different from gender qualification in Bugis society. In Bugis society gender has five categories: Oroane is man either physically or its role in every day live; makkunrai is a woman either physically or its nature as woman; calalai is a woman behaves as a man; calabai is a man behaves as a woman.

Bissu is a group does not belong to the four above genders. The performance of Bissu is very special because of its costume. This group wear neither man or woman costumes.Traditional Bugis society consider Bissu as combination of the four above gender. Not all Calalai or Calabai can become a Bissu. Being a Bissu is gods gift. Bugis society respect higly to Bissu, because Bissu has knowledge about tradition, family root, social life, traditional mystical cure and the life of gods. Bissu is able to communicate with the deaths and gods. Because Bisu is considered as a holy creature, they have an exlusive life.

At present, the number and activities of Bissu is decreasing because of the changing of the government sytem: from monarchy to republic, the DI/TII rebellion in 1950, that wanted to abolish Bissu existence due to the abuse of Islamic law.
\end{abstract}

Key word: Bissu, gender, budaya, Bugis

\section{Pendahuluan}

Etnis Bugis sebagai salah satu etnis di Indonesia, memiliki banyak keunikan yang tidak dimiliki oleh etnis-etnis lain. Salah satu keunikan tradisi etnis Bugis adalah tradisi yang berasal dari masa pra Islam dan masih berlangsung sampai saat ini yaitu keberadaan Bissu. Keistimewaan Bissu adalah spesifikasi gendernya, yang tidak masuk pada kategori laki-laki maupun perempuan.

Bissu adalah sekelompok orang yang memiliki hubungan dengan dunia mistik. Peran Bissu di dalam masyarakat Bugis sangat penting dan mereka memiliki status yang tinggi.

Masyarakat Bugis mempercayai bahwa Bissu memiliki kekuatan supra natural dan dianggap sebagai manusia sakti. Tugas dan peran Bissu dalam setiap upacara adat Bugis adalah sebagai pendeta atau pemangku adat (Trianto, $2003: 1$ ).

Menurut kepercayaan masyarakat Bugis, Bissu hadir bersamaan dengan kelahiran suku Bugis. Dalam kitab I La Galigo disebutkan bahwa, keberadaan Bissu berkaitan dengan cerita legenda tentang Batara Guru yang menjadi cikal bakal manusia Bugis turun dari "dunia atas" (botinglangi) ke bumi atau dunia bawah (bori'liung) untuk menemui istrinya We Nyili Timo. Ketika Batara Guru turun ke bumi, ia disertai seorang Bissu yang bernama Lae-lae. Bissu ini 
membantu Batara Guru untuk mengatur kehidupan di bumi. Berkat bantuan Bissu, di bumi tercipta aturan, norma dan etika masyarakat. Selain itu juga tercipta bahasa dan karya-karya budaya dan tradisi sebagai hasil kegiatan masyarakat (Kern, $1993: 34$ )

Mengutip dari Abdullah (1985), masyarakat Bugis pada masa awal sejarah mempunyai sistem kepercayaan yang memuja dewa tertinggi atau To PalanroE. Sistem kepercayaan ini disebut attoriolong, yang berarti "mengikuti tata cara leluhur". Melalui attiorolong diwariskan nilai-nilai, petunjuk-petunjuk, aturan-aturan dan norma dalam kehidupan masyarakat. Sampai sekarang, masyarakat Bugis masih ada yang melakukan kepercayaan ini.

Dalam attoriolong, Bissu adalah perantara antara langit dengan bumi, karena Bissu menguasai Basa Torilangi, atau bahasa langit yang hanya dimengerti oleh Bissu dan para dewa. Lewat bahasa mistik tersebut, Bissu membacakan mantra dan doa dalam berbagai upacara keagamaan baik bersifat kenegaraan atau kelompok masyarakat dan keluarga. Upacara-upacara adat yang digelar Bissu biasanya berkaitan dengan penetapan hari baik untuk mengadakan acara penting, seperti waktu untuk mulai menanam padi, waktu seseorang akan melakukan perjalanan haji, waktu yang baik untuk membangun rumah, penobatan pemimpin atau raja dan lain sebagainya (Yaurie, 2008 : 23). Masyarakat tradisional Bugis pada masa lalu, sangat percaya bahwa bila ada raja yang tidak didoakan oleh Bissu, maka raja tersebut tidak memiliki kewibawaan dalam memimpin rakyatnya (Mujahiduddin, 2004: 54)..

Pada masa pemerintahan kerajaan-kerajaan pra-Islam di Sulawesi Selatan, telah ditetapkan , bahwa setiap ranreng yaitu semacam wilayah adat (kini kecamatan) diharuskan memiliki suatu komunitas Bissu. Kerajaan Segeri dan kerajaan Bone saat itu dikenal memiliki komunitas Bissu dengan sebutan Bissu PatappuloE, yaitu komunitas Bissu yang memiliki anggota 40 orang Bissu.

Saat ini keberadaan Bissu semakin berkurang. Di beberapa ranreng jumlah Bissu tidak ada yang bisa mencapai jumlah minimal tersebut. Di Segeri misalnya, kini hanya terdapat tak lebih dari empat orang Bissu. Beberapa Bissu masih dapat dijumpai di Luwu, Sigeri, Bone, Wajo, Soppeng, Pinrang, Sidenreng Rappang, Pare-pare dan Makassar (Hartarini, 2012 : 208)

Berkurangnya jumlah Bissu disebabkan oleh beberapa faktor, baik faktor internal maupun eksternal. Faktor internal adalah menurunnya minat orang untuk menjadi Bissu, karena syarat-syarat yang berat. Faktor ekternal adalah karena perubahan sistim pemerintahan, dari pemerintahan kerajaan menjadi pemerintahan republik. Pada masa kerajaan kehidupan Bissu ditopang oleh kerajaan yang memberikan kemudahan dalam kehidupan ekonomi dan status sosial yang tinggi. Hal ini berubah ketika pemerintahan negara berbentuk republik, yang mengatur pemerintahan daerah dilaksanakan oleh kepala daerah sesuai dengan jenjang hirarkinya dengan masa jabatan yang telah ditentukan. Sejak perubahan status kerajaan menjadi Negara Kesatuan Republik Indonesia, Bissu tidak memiliki sumber ekonomi, karena galung arajang (sawah pusaka) sebagai sumber penghasilan Bissu telah diambil alih oleh masyarakat atau pemerintah daerah. Ketiadaan sumber ekonomi menyebabkan bola arajang (rumah pusaka) sebagai tempat kediaman Bissu menjadi tidak terawat dan mulai rusak dan ditinggalkan oleh para Bissu.

\section{Metode}

Artikel ini merupakan kajian tentang kehidupan Bissu dilihat dari aspek sejarah. Pendekatan kajian menggunakan metode sejarah yang tahapannya dimulai dari heuristik, kritik sumber, interpretasi dan historiografi.

Pada tahap pertama yaitu heuristik dilakukan pengumpulan data dan sumber-sumber sejarah,yang dalam hal ini menggunakan sumber-sumber sekunder yang berupa buku-buku 
dan artikel dari beberapa penulis dan peneliti sejarah. Tahap kedua adalah melakukan kritik atau penilaian terhadap sumber-sumber yang telah diperoleh. Kritik sumber dilakukan secara intern dan ekstern. Kritik ektern untuk menguji tingkat otentisitas serta melihat keakuratan hasil-hasil penelitian yang dipublikasikan, yang dipakai sebagai sumber informasi dalam kajian ini. Kritik intern untuk menguji kredibilitas informasi yang terkandung di dalamnya.

Interpretasi dilakukan untuk menafsirkan masing-masing data dan kemudian disusun dan dihubungkan satu data/informasi dengan data/informasi yang lain. Fakta-fakta yang muncul kemudian dihubungkan sehingga diperoleh gambaran yang utuh tentang kehidupan Bissu di Sulawesi Selatan. Tahap akhir dari metode sejarah adalah historiograsi yaitu menyusun dan menuliskan fakta-fakta sejarah yang bersifat deskriptif analitis.

Metode penelitian sejarah digunakan dengan tujuan agar dapat melihat secara lebih jelas proses kemunculan, perkembangan, dinamika, perubahan serta alur sejarah Bissu di lingkungan masyarakat Bugis di Sulawesi Selatan.

\section{Hasil dan Pembahasan}

\subsection{Gender dalam Budaya Bugis}

Secara umum pembagian gender di dalam lingkungan masyarakat etnis-etnis di Indonesia, yang diakui adalah laki-laki dan perempuan. Hal ini berbeda dengan pembagian gender di lingkungan etnis Bugis. Davies (2017: 219-310) menyebutkan, bahwa gender dalam masyarakat Bugis yang diakui ada lima kategori, yaitu: (1) Oroane adalah laki-laki, baik secara fisik, maupun perannya dalam kehidupan kesehariannya. Ia tampil maskulin dan mampu menjalin hubungan dengan perempuan. (2) Makkunrai adalah perempuan, baik secara fisik maupun kodratnya sebagai perempuan, yang bisa jatuh cinta dan menikah dengan lakilaki, melahirkan dan mengurus anak dan keluarganya dan sebagainya. (3) Calalai adalah perempuan yang berpenampilan seperti laki-laki. Ia secara fisik adalah perempuan, tetapi mengambil peran laki-laki dalam kehidupan kesehariannya, misalnya ia bekerja di lingkungan laki-laki dan melakukan pekerjaan-pekerjaan berat seperti yang dilakukan laki-laki. (4) Calabai adalah laki-laki yang berpenampilan seperti perempuan. Ia terlahir sebagai laki-laki, tetapi mengambil peran dalam pekerjaan-pekerjaan yang dilakukan perempuan. Calabai berpenampilan sangat feminin. (5) Kelompok gender yang tidak termasuk pada ke empat golongan tersebut, adalah gender yang disandang oleh Bissu. Bissu adalah golongan yang tidak memiliki gender, ia bukan laki-laki, bukan perempuan, bukan lesbian dan bukan banci. Penampilan Bissu sangat istimewa, karena ia berpakaian tidak seperti laki-laki dan tidak seperti perempuan. Ia mengenakan pakaian khusus, yang hanya dikenakan oleh Bissu.

Masyarakat Bugis tradisional menganggap Bissu sebagai kombinasi dari semua jenis gender tersebut, sejauh mereka menjalankan fungsi dan perannya di dalam masyarakat dengan baik. Masyarakat sering salah menafsirkan gender yang disandang Bissu, yang disamakan dengan calabai (banci). Masyarakat Bugis sangat menghormati Bissu, walaupun status gendernya tidak menunjukkan gender yang umum ada di lingkungan masyarakat. Hal ini berbeda dengan pandangan masyarakat di luar masyarakat Bugis terhadap banci dan lesbian. Banci dan lesbian selalu menjadi bahan olok-olok dan ejekan masyarakat karena gender yang mereka sandang dianggap sebagai ketidaknormalan dan menyalahi kaidah-kaidah agama.

Sebagai kelompok yang tidak masuk pada gender Oroane dan Makunrai, Bissu memiliki kebebasan untuk masuk ke wilayah kedua gender tersebut. Keistimewaan dan keunikan Bissu ini ditampilkan dalam pakaiannya yang memperlihatkan unsur-unsur perempuan dan laki-laki (Syamsuddin, 2010: 75). Masyarakat Bugis memberikan 
penghormatan yang tinggi kepada Bissu bukan pada aspek gendernya, tetapi pada peran sosialnya sebagai pelestari tradisi dan budaya Bugis .

Saat ini sebagian besar Bissu adalah calabai (laki-laki yang memiliki sifat dan menjalankan peran sebagai perempuan), tetapi tidak semua calabai bisa menjadi Bissu (Latief. 2004 : 39). Menurut Latief (2004: 38), kata calabai berasal dari kata cala/sala yang artinya "bukan" dan kata bai/baine yang artinya "perempuan". Jadi kata calabai artinya bukan perempuan. Berbeda dengan Latief, banyak orang yang mengartikan kata calabai berasal dari kata cala/sala yang artinya "salah", dan kata bai yang artinya "senggama". Jadi kata calabai artinya adalah senggama yang salah atau tidak normal.

Dalam masyarakat Bugis ada beberapa kategori calabai, yaitu: (1) Calabai tunngke'na lino adalah Calabai yang menduduki tingkat paling tinggi, yang dirahmati oleh Dewata. Calabai tunngke'na lino berjenis kelamin laki-laki, tetapi ia memiliki jiwa dan pembawaan perempuan. Ia tidak memiliki rasa cinta dan hasrat sexual terhadap perempuan. Ia dianggap memiliki keistimewaan sebagai orang yang bisa berhubungan dengan dewata dan alam roh. Oleh karena itu ia dianggap sebagai guru. Calabai tunngke'na lino inilah yang menjadi Bissu. (2) Pa'calabai adalah laki-laki yang pembawaannya seperti perempuan, tetapi ia memiliki orientasi sexual ganda. Ia dapat berhubungan sexual dengan laki-laki maupun perempuan. (3) Calabai kedo-kedonami yaitu orang yang hanya meniru gaya para calabai. Jarang terjadi Bissu dari jenis gender Makunrai (perempuan). Kalaupun ada, biasanya berasal dari kalangan bangsawan atau keluarga raja (Latief, 2004 : 39).

\subsection{Proses Kelahiran Bissu}

Tidak semua orang yang menyandang gender Calabai atau Calalai bisa menjadi Bissu. Masyarakat Bugis percaya, bahwa menjadi Bissu adalah anugerah Dewata. Anugerah ini disampaikan melalui firasat yang berupa mimpi atau sakit. Tanda-tanda yang tampak jika seseorang "terpilih" menjadi Bissu, yaitu sejak masa kanak-kanak ada kecenderungan memiliki gender ganda dan memiliki keunikan yang berhubungan dengan dunia gaib. Anakanak dengan keunikan-keunikan ini dipersiapkan untuk menjadi Bissu. Hartarini (2012 : 209) menyebutkan, bahwa untuk membuktikan bahwa anak tersebut telah menerima anugerah dan berkat dari Dewata, maka ketika ia dewasa, ia harus menjalani prosesi sebagai syarat yang tergolong berat untuk menjadi Bissu, yaitu: (1) Ia harus berpuasa "mutih", yaitu hanya makan nasi putih tanpa lauk dan air putih selama 7 (tujuh) hari atau berpuasa biasa selama 40 hari di bola arajang (rumah tempat menyimpan pusaka). (2) Setelah berpuasa, ia harus melakukan mattinja' (bernazar) dan harus lancar menuliskan dan melafalkan Sureq Galigo. Rajah huruf Bugis kuno tersebut dipercaya kelak dapat menjadi alat dalam menjalankan tugas dan pekerjaannya. (3) Setelah melaksanakan mattinja', calon Bissu harus menjalani prosesi irebba (dibaringkan) di loteng bola arajang yang berlangsung selama 3 atau 7 hari. (4) Pada hari terakhir prosesi calon bissu akan dimandikan, dikafani dan dibaringkan selama sehari dari pagi hingga petang. Di atas tubuhnya digantung sebuah guci berisi air yang telah di-mabessi (disucikan) dengan upacara sakkatolo (sepakat). Selama berbaring, calon Bissu diperdengarkan lantunan Sureq Galigo. (5) Pada petang hari guci yang digantung di atas tubuh calon Bissu dipukul oleh Puang Matowa hingga airnya membasahi tubuh calon Bissu yang sedang irebba. (6) Setelah melewati prosesi sakral itu, seorang calabai resmi menjadi Bissu.

Masyarakat Bugis percaya, bahwa jika upacara sakral ini telah direstui oleh Dewata, maka pada malam terakhir irebba akan turun hujan deras. Bila pada malam terakhir irebba tidak turun hujan, maka prosesi irebba harus diulang. Hujan merupakan tanda bahwa penobatan Bissu sudah mendapat restu Dewata. Setelah dinobatkan secara sah, Bissu harus 
tampil malebbi (anggun dan bersahaja) dan senantiasa berlaku santun. Selain itu Bissu harus bisa menjadi teladan di lingkungan masyarakatnya. Untuk itu para Bissu dituntut hidup saleh, dapat menjaga sikap yang terpuji, berperilaku dan bertutur kata santun dan menjaga etika.

Berdasarkan proses kelahirannya, ada 2 (dua) kategori Bissu, yaitu: (1) Bissu Dewata adalah Bissu yang kelahirannya melalui titah dari Dewata. Bissu Dewata memiliki ilmu gaib dan pengetahuan adat serta tradisi yang tinggi. Biasanya Bissu Dewata inilah yang akan menjadi Puang Matowa atau Puang Towa (pemimpin Bissu). (2) Bissu Mamata adalah Bissu biasa yang terbentuk secara alamiah melalui proses kesehariannya bergaul dengan para Bissu dan karena panggilan jiwanya.

Dalam komunitas Bissu ada beberapa gelar khusus, yang menunjukkan keahlian dari para Bissu tersebut. Bissu yang memiliki keahlian mengobati atau yang berperan sebagai dukun disebut Sanro. Bissu yang dapat berkomunikasi dengan roh dengan menggunakan bahasa Dewata disebut Bissu Dewata'e. Bissu yang berasal dari keturunan bangsawan disebut Bissu Patudang.

\subsection{Peran Bissu Dalam Tradisi Bugis}

Peran Bissu yang sangat istimewa tampak dari namanya, yaitu Bissu berasal dari kata "bessi" yang artinya bersih dalam arti yang luas. Ia tidak berdarah, suci, tidak mengalami menstruasi dan tidak menyusui (Ad'ham, 2009: 403).

Menurut Pelras (2006 : 68), ada kemungkinan kata Bissu berasal dari kata Bhiksu (pendeta atau pimpinan agama Budha). Pada masa pra Islam agama Budha sudah berkembang di lingkungan masyarakat Bugis, sehingga ada kemungkinan bahasa Sanskerta juga meresap ke dalam bahasa Bugis. Hal ini juga ditandai oleh fungsi Bhiksu yang hampir sama dengan Bissu.

Hamonic (1986) menyebutkan bahwa, masyarakat Bugis sangat menghormati Bissu karena Bissu memiliki pengetahuan tentang adat istiadat, tradisi, silsilah keluarga, kehidupan sosial di dunia dan kehidupan para dewata, menguasai pengobatan dan mistik. Masyarakat dan keluarga kerajaan sering meminta petunjuk, pertolongan, ataupun berobat dan berguru kepada Bissu. Bissu dahulu mendapat perlakuan khusus karena peranan mereka dalam menentukan hajat hidup masyarakat Bugis. Bissu memiliki peran sosial yang terkait dengan kepercayaan bahwa bissu dapat berhubungan dengan arwah leluhur dan para dewata. Masyarakat sering meminta jasa Bissu untuk menghubungkannya dengan arwah leluhur atau para dewata untuk memenuhi permintaan-permintaan mereka. Karena keistimewaankeistimewaan yang dimiliki Bissu, maka ia dianggap keramat (makarama) oleh masyarakat di lingkungannya. Untuk menjaga makarama, para Bissu hidup secara ekslusif dan membatasi pergaulan sosialnya dengan masyarakat. Mereka hanya menjalin pergaulan yang erat dengan sesama Bissu (Bahfiarti, 2011 : 167)

Pada masa pra Islam, ketika kerajaan-kerajaan Bugis berjaya, para Bissu mendapat penghargaan yang tinggi dari raja. Salah satu penghargaan kerajaan adalah pemberian gelar "Puang”. Selain gelar, seorang Puang Matowa (pimpinan atau ketua komunitas Bissu) diberi sawah (galung arajang) yang luas. Sawah yang luasnya beberapa hektar ini dikerjakan oleh masyarakat secara gotong royong. Hasil sawah ini digunakan untuk membiayai kegiatan upacara-upacara adat yang dipimpin Bissu dan untuk membiayai komunitas Bissu yang ada di wilayah kekuasaan kerajaan tersebut. Selain dari hasil sawah, untuk memenuhi kebutuhannya, Bissu juga mendapat sumbangan atau sedekah dari masyarakat. Sebagai tempat tinggal Bissu diberi oleh raja rumah yang disebut bola arajang. Bola arajang selain berfungsi sebagai tempat tinggal Bissu, juga berfungsi sebagai tempat berkumpul para Bissu dalam melakukan kegiatan ritual dan tradisi dan sebagai tempat untuk menyimpan arajang . 
Peran Bissu pada masa kerajaan-kerajaan Bugis kuno sangat besar. Bissu pada masa itu masuk dalam lingkaran birokrasi kerajaan. Para Bissu ini diberi jabatan sebagai penasihat spiritual raja (Makkulau, 2007: 41). Bahkan para Bissu diberi kewenangan untuk menobatkan raja (Syamsuddin, 2010: 5). Masyarakat percaya bahwa doa yang dilakukan Bissu sangat berpengaruh pada kewibawaan raja. Selain itu para Bissu juga diberi tugas sebagai pemuka adat dan sebagai pimpinan kepercayaan Bugis pra Islam. Semua kebijakan dan keputusan raja saat itu didasari oleh persetujuan dan pertimbangan dari Bissu, misalnya ketika raja akan melakukan perang dengan kerajaan lain, raja berkonsultasi terlebih dahulu dengan Bissu. Bissu juga memiliki kewenangan untuk menentukan hari-hari baik untuk memulai pekerjaanpekerjaan besar dan penting, misalnya untuk pembangunan rumah atau rumah ibadah, perjalanan-perjalanan penting, memulai pekerjaan di sawah dan lain sebagainya. Bissu juga memimpin upacara-upacara adat seperti upacara pernikahan, kehamilan, kelahiran, kematian, persembahan, tolak bala, nazar dan lain sebagainya.

Di antara sekian banyak tugas Bissu yang sangat lekat dengan tugas-tugas kerajaan, yang tidak kalah penting adalah tugas merawat dan menjaga pusaka kerajaan, yang disebut arajang. Masyarakat Bugis mempercayai bahwa arajang adalah benda-benda pusaka yang diturunkan dewata dari langit. Arajang seringkali juga disebut sebagai alameng atau palakka. Arti kata arajang dalam bahasa Bugis adalah keagungan, kemuliaan dan kebesaran. Karena dianggap benda yang sangat suci dan bertuah, yang menjadi simbol kekuatan supranatural, maka arajang diberi nama kehormatan seperti nama manusia terhormat. Ada arajang yang diberi nama Puang Bekeru, Bakaka, PongoroE, Sapadilae, dan Cakkuridi. Benda-benda arajang yang menjadi pusat penghormatan dalam acara-acara yang dipimpin Bissu bentuknya bermacam-macam, seperti keris, tombak, bajak sawah (rakkala) dan lain sebagainya (Makkulau 2008: 56).

Menurut Latief ( 2004 : 47) hirarki dalam komunitas Bissu menurut peran dan tugasnya dapat dibedakan:

Pertama, Puang Matowa merupakan Bissu yang menduduki lapisan tertinggi dalam komunitas Bissu. Ia diangkat oleh masyarakat dan disahkan sebagai pimpinan Bissu oleh raja. Tugas sebagai Puang Matowa adalah merawat dan menjaga pusaka kerajaan serta memberikan pelayanan kepada keluarga kerajaan. Karena tugasnya ini, seluruh biaya hidup Puang Matowa ditanggung oleh kerajaa. Puang Matowa bertempat tinggal di Bola Arajang yaitu rumah tempat untuk menyimpan pusaka kerajaan. Dalam upacara-upacara tradisi Puang Matowa sebagai pimpinan Bissu, harus selalu hadir. Jika Puang Matowa berhalangan hadir dalam suatu upacara, maka ia akan digantikan oleh Puang Lolo, yang kedudukannya di bawah Puang Matowa.

Kedua, Puang Lolo, yaitu Bissu yang kedudukannya di bawah Puang Matowa. Sebagai wakil dari Puang Matowa, Puang Lolo memiliki keahlian yang tidak jauh berbeda dari Puang Matowa. Pelantikan Puang Lolo dilakukan bersamaan dengan pelantikan Puang Matowa, karena Puang Lolo pun dipilih oleh rakyat dan dilantik oleh raja. Puang Lolo inilah yang akan menggantikan Puang Matowa menjadi Bissu, bila Puang Matowa meninggal dunia. Hubungan antara Puang Matowa dan Puang Lolo yang demikian erat sebagai dwitunggal disebut anreguru yaitu guru yang mendidik muridnya (Ana'Bissu)

Ketiga, Bissu Tantre adalah Bissu yang mempunyai kecerdasan tinggi dan pengetahuannnya tentang upacara tradisi dan hal-hal gaib juga tinggi. Pengajaran dan ilmuilmu yang diturunkan oleh Puang Matowa cepat diserap oleh Bissu Tantre .

Keempat, Bissu Poncok adalah Bissu yang menempati strata terendah karena dianggap derajat pengetahuan dan ketrampilannya rendah. Bissu Poncok memiliki kemampuan terbatas (rendah) untuk menyerap ilmu dan ketrampilan yang diajarka oleh Puang Matowa. 
Karena masyarakat Bugis merupakan masyarakat yang masih mengandalkan mata pencahariannya di bidang pertanian, maka kegiatan pertanian menjadi kegiatan yang penting. Untuk kegiatan pertanian ini diadakan upacara adat mappalili atau turun ke sawah. Upacara mappalili adalah upacara adat yang dilaksanakan sebelum masa tanam padi. Pada upacara adat mappalili ini peran Bissu sangat dominan. Bissu memimpin upacara mappalili, yang berlangsung selama 7 (tujuh) hari 7 malam dengan membacakan mantera Mattesu Arajang yaitu mantra untuk memohon restu para dewa agar hasil pertanian melimpah (Syahrir, 1996: 68- 75).

Pelaksanaan upacara tradisi mappalili pada awalnya berlangsung selama 40 hari 40 malam dan dihadiri oleh 40 orang Bissu. Seiring dengan perubahan jaman dan keterbatasan waktu yang dimiliki masyarakat, upacara mappalili dipersingkat. Seluruh pembiayaan upacara mappalili ditanggung oleh Bissu dan masyarakat. Puncak acara mappalili adalah magiri, yaitu perilaku Bissu yang menusuk tubuhnya dengan badik (senjata tajam khas Bugis). Pada upacara mappalili dan upacara masongla bala (tolak bala), kegiatan maggiri merupakan atraksi yang memperlihatkan kesaktian para Bissu yang tubuhnya tidak bisa ditembus atau dilukai oleh senjata tajam.

Sampai saat ini peran Bissu masih tampak, terutama pada generasi usia lanjut (usia 50 tahun ke atas). Pada kelompok usia ini banyak yang mempercayai, bahwa Bissu dapat berperan sebagai penghubung antara orang-orang yang masih hidup di dunia dengan para leluhurnya yang sudah meninggal, dengan tujuan mendapatkan berkah dan memenuhi harapan mereka. Pada generasi muda, keberadaan Bissu tidak menimbulkan pengaruh yang berarti. Para generasi muda tidak lagi menaruh perhatian pada eksistensi dan kredibilitas Bissu.

\subsection{Kehidupan Bissu Saat Ini}

Pada jaman kerajaan-kerajaan Bugis masih berjaya, komunitas Bissu terdapat hampir di semua daerah-daerah Bugis di Sulawesi Selatan. Saat ini komunitas Bissu yang masih bertahan terdapat di kecamatan Sigeri Kabupaten Pangkep.

Jumlah Bissu saat ini menurun drastis. Beberapa peristiwa yang menyebabkan jumlah dan aktivitas Bissu menurun yaitu antara lain ketika Indonesia memperoleh kemerdekaaannya pada tahun 1945, sistim pemerintahan yang dianut adalah republik, yang kemudian menghapus sistim kerajaan. Perubahan sistim pemerintahan ini berdampak pada kehidupan Bissu, yang selama ini bersandar pada kekuasaan raja (Ad'han 2010: 21).

Kehidupan Bissu yang semakin suram terjadi pada masa munculnya gerakan kelompok DI/TII di Sulawesi Selatan sekitar tahun 1950-an, yang berusaha mengadakan pemurnian terhadap ajaran-ajaran Islam. Kelompok DI/TII menganggap aktivitas Bissu sebagai hal yang menyalahi aturan agama Islam dan dikategorikan sebagai hal musrik. Para anggota kelompok DI/TII berusaha melarang aktivitas Bissu dan menghancurkan peralatan upacara milik para Bissu. Bahkan banyak Bissu yang dibunuh, karena dianggap menyalahi kodrat dan tidak mau bertobat. Masa ini merupakan masa yang kelam bagi kehidupan Bissu (Latief, 2004: 79-80).

Pada masa awal pemerintahan Orde Baru, tahun 1966 para Bissu mendapat tekanan dari pemerintah, karena ada issue bahwa para Bissu adalah bagian dari PKI. Pemerintah Orde Baru juga mengadakan Operasi Toba (operasi taubat), yang memaksa para Bissu menjadi lakilaki tulen. Para Bissu diburu dan banyak yang dibunuh. Masyarakat pada umumnya tidak bisa berbuat bayak untuk melindungi para Bissu tersebut. Bissu yang tersisa saat ini adalah Bissu yang bisa bersembunyi dan menyelamatkan diri waktu itu.

Setelah beberapa peristiwa yang menyedihkan tersebut, komunitas Bissu tidak lagi melaksanakan upacara Mappalili. Ketika hasil panen masyarakat kurang memuaskan, mereka menganggap bahwa hal ini disebabkan oleh upacara Mappalili yang tidak lagi dilakukan. 
Beberapa kelompok masyarakat menyadari, bahwa mereka harus menghidupkan kembali upacara Mappalili untuk mengembalikan kesejahteraan masyarakat Bugis. Upacara Mappalili kemudian dilaksanakan kembali dengan sederhana dan waktu upacara yang lebih singkat. Bila sebelum masa pemberontajan DI/TII dan masa Orde Baru, upacara Mappalili melibatkan sedikitnya 40 orang Bissu dan dilaksanakan selama 40 hari, maka saat ini upacara Mappalili hanya bisa dihadiri oleh 20 orang Bissu saja dan waktu pelaksanaannya hanya 1 hari.

Perkembangan agama Islam di Sulawesi Selatan yang pesat juga menyebabkan perubahan terhadap aktivitas Bissu. Umat Islam di Sulawesi Selatan, menganggap Bissu adalah orang-orang yang menyalahi kodrat dan mereka dianggap kafir. Bahkan tradisi-tradisi yang dilaksanakan oleh Bissu dianggap musyrik. Untuk menghadapi cemohan dan pandangan negatif masyarakat, para Bissu terpaksa menyesuaikan diri dengan kondisi masyarakat Sulawesi Selatan yang agamis. Banyak Bissu yang telah menjalankan syariat Islam lebih mendalam, bahkan banyak pula yang telah menjalankan ibadah haji. Untuk menunjukkan tingkat ketaatan mereka terhadap Islam, Bissu telah merubah penampilannya, yaitu dengan menggunakan pakaian yang Islami seperti mengenakan jubah putih dengan sorban, seperti pakaian yang dikenakan para ulama atau haji (Syahrul, 2013 : 96).

Pada masa-masa setelah Orde Baru, kehidupan Bissu semakin sulit, karena bola arajang, sebagai tempat berkumpulnya komunitas Bissu semakin tidak terawat dan kepemilikannya beralih kepada masyarakat. Demikian juga galung arajang (sawah arajang sebagai sumber penghidupan para Bissu juga diambil alih oleh pemerintah dan masyarakat. Kehidupan Bissu semakin suram ketika pada masa-masa selanjutnya beberapa Puang Matowa meninggal dunia dan belum dipilih penggantinya. Kesulitan ekonomi dan ketiadaan pimpinan menyebabkan Bissu mencari penghidupan masing-masing dan tinggal terpencar-pencar.

Salah seorang Bissu yaitu Puang Ummasse yang tetap setia merawat arajang di rumah pribadinya, berusaha untuk tetap melaksanakan upacara-upacara dan tradisi Bissu sampai terpilihmya Puang Matowa yang baru. Baru pada tahun 2001 terpilih Puang Matowa Saidi dan wakilnya yaitu Puang Lolo Upek. Mereka berdualah yang berusaha keras menghidupkan kembali tradisi Bissu yang telah kehilangan pamornya.

Usaha dari generasi terakhir Bissu tidak terlalu menggembirakan, karena para sesepuh Bissu, terutama para Puang Matowa banyak yang sudah meninggal dunia dan para Bissu penerusnya tidak memiliki daya yang kuat untuk menghidupkan tradisi Bissu. Saat ini Bissu hidup dalam beberapa komunitas yang terdapat di beberapa daerah, salah satunya adalah daerah Sigeri kabupaten Pangkep. Di daerah Sigeri ini para Bissu saat ini mencari nafkah dengan menjadi perias pengantin (indo botting), menyewakan peralatan dan perlengkapan pengantin, menjadi penjahit pakaian adat dan pakaian pengantin, menjadi petani serta pekerjaan-pekerjaan lain. Selain itu para Bissu untuk membiayai kehidupan sehari-hari, hanya mengharap pemberian orang-orang yang melakukan nadar karena hasil panen atau usahanya berhasil atau orang-orang yang meminta doa agar usaha dan niatnya berhasil.

Menurut Latief (2004), faktor-faktor yang mempengaruhi penurunan peran dan fungsi komunitas bissu yaitu, faktor internal dan faktor eksternal. Faktor internal yaitu generasi muda jarang yang berminat untuk menjadi Bissu, sehingga tidak ada regenerasi dalam pelestarian tradisi Bissu. Terbatasnya Bissu yang mumpuni dan berwibawa, yang dapat dijadikan Puang Matowa, menjadikan komunitas Bissu ini semakin terpinggirkan dalam struktur dan kultur masyarakat Bugis yang pernah mengagungkannya.

Faktor eksternal yang menyebabkan merosotnya komunitas Bissu, yaitu antara lain masyarakat dan pemerintah tidak lagi memposisikan bissu sebagai sebuah masyarakat adat. Faktor eksternal yang lain adalah perubahan sistem kenegaraan, dari sistem kerajaan menjadi negara kesatuan, yang menyebabkan peran raja digantikan oleh kepala daerah seperti bupati 
atau camat, yang menjabat dalam waktu tertentu. Hal ini menyebabkan Bissu tidak memiliki sandaran otoritas yang mengakui keagungan dan kesuciannya.

Pemerintah daerah di beberapa daerah yang memiliki komunitas Bissu, kurang memberikan perhatian kepada komunitas Bissu sebagai bagian dari tradisi dan adat Bugis. Dewasa ini pemerintah daerah hanya memandang Bissu sebagai bagian dari tradisi masa lalu, yang fungsinya sebagai bagian dari adat dan tradisi sudah mulai memudar.

Masyarakat Bugis saat ini kurang memahami keistimewaan gender para Bissu sehingga kepercayaan masyarakat terhadap kesakralan fungsi Bissu mulai memudar. Pemahaman agama masyarakat yang memandang Bissu sebagai penyimpangan, menyebabkan komunitas Bissu semakin tersingkir.

Sekarang sudah sangat jarang orang yang melakukan upacara-upaca adat dengan menggunakan jasa Bissu. Kalaupun Bissu masih tampil dalam upacara adat, biasanya berkaitan dengan kepentingan pariwisata dan kepentingan politik untuk ditampilkan dalam acara kampanye pemilihan kepala daerah atau pemilihan partai.

\section{Simpulan.}

Perjalanan sejarah yang panjang, yang telah dilalui Bissu, menunjukkan bahwa ada keterikatan sosial yang kuat antara Bissu dan masyarakat. Ikatan sosial ini menunjukkan betapa besar peran Bissu dalam masyarakat, yang diekspresikan pada setiap upacara adat yang dilaksanakan untuk tujuan memperoleh kemakmuran dan kesejahteraan.

Sejarah membuktikan, bahwa tekanan dan hambatan yang dialami Bissu dalam memperjuangkan eksistensinya tidak membuat komunitas Bissu sirna, walaupun keadaan Bissu juga tidak bisa sama dengan keadaan sebelum terjadi perubahan pemerintahan dari kerajaan menjadi republik, sebelum terjadinya pemberontakan DI/TII dan sebelum masa Orde Baru.

Dalam hal ini, yang tidak kalah penting adalah perjuangan para Bissu menghadapi kecaman para pemuka agama, yang menganggap keberadaan Bissu secara fisik dan ritual adat yang dilakukannya bertentangan dengan ajaran Islam. Untuk meredam kecaman para pemuka agama ini, para Bissu menjadi pemeluk Islam dan melaksanakan syariat Islam, walaupun setiap tahun mereka juga tetap melaksanakan upacara adat mappalili.

Di era modern ini peran Bissu mulai menurun, kepercayaan dan penghormatan masyarakat juga mulai surut, sehingga pamor Bissu memudar. Bissu sekadar dipahami dan disamakan dengan banci biasa, yang tidak memiliki keistimewaan. Fungsi dan peran Bissu saat ini lebih banyak untuk komoditas wisata atau hiburan dan tontonan dengan mengabaikan posisinya sebagai orang suci dalam masyarakat adat.

Walaupun keadaan telah berubah komunitas bissu tetap eksis dengan segala kekurangannya. Jumlah Bissu yang semakin menyusut dan pelaksanaan upacara adat yang tidak teratur menyebabkan regenerasi bissu tidak terjadi. Kejayaan Bissu yang semakin surut membawa dampak pada pelestarian budaya dan tradisi Bugis lainnya. Komunitas Bissu sebagai identitas budaya Bugis, yang telah mengakar dalam kehidupan masyarakat dikhawatirkan akan punah. Untuk menjaga kelestariannya diharapkan pemerintah daerah yang memiliki komunitas Bissu di daerahnya, memikirkan dan bertindak secara bijak bagaimana caranya agar budaya Bissu tetap eksis di tengah masyarakat modern.

\section{Daftar Pustaka}


Abdullah, Hamid. 1985. Manusia Bugis Makassar: Suatu Tinjauan Historis terhadap Pola Tingkah Laku dan Pandangan Hidup Manusia Bugis Makassar, Jakarta: Inti Idayu Press.

Ad'ham, S. dan Mabrur, M. 2010. Menjajakan Bissu: Siapa Yang Untung? dalam Agama dan Kebudayaan, Jakarta: Desantara Foundation.

Ad'han, S. Bissu 2009. yang Enggan Membisu, Jurnal "Al-Qalam" Volume 15 Nomor 24 Juli - Desember 2009, Ujung Pandang: Balai Penelitian Lektur Keagamaan.

Baftiarti, Tuti. 2011. Mistifikasi 'Bissu' Dalam Upacara Ritual Adat Etnik Bugis Makassar (Kajian Studi Dramaturgi) dalam Jurnal Ilmu Komunikasi, Vol. 1, No.2, Oktober 2011, ISSN: 2088-981X.

Davies, Sharyn Graham. 2017. Keberagaman Gender di Indonesia (Pemerjemah : Santi Hendrawati dan Catharina Indirastuti). Jakarta : Yayasan Pustaka Obor Indonesia

Kern, R.A. 1993. I La Galigo. Yogyakarta: Gadjah Mada University Press.

Latief, H. 2004. Bissu; Pergulatan dan Peranannya di Masyarakat Bugis, Depok: Desantara Utama.

Latief, H. 2005. Kepercayaan Asli Bugis di Sulawesi Selatan, Sebuah Kajian Antropologi Budaya, Makassar: Universitas Hasanuddin Press.

Hamonic, Gilbert Albert. 1986. La Galigo, Menelusuri Jejak Warisan Sastra Dunia, Jakarta : Pustaka Media.

Hartarini, Yovita M. 2012. Komunitas Adat Bissu : Waria Bertalenta Sakti Sebuah Analisis Sosio-Budaya Etnis Bugis - dalam Majalah Ilmiah INFORMATIKA Vol. 3 No. 2, Mei 2012, Fakultas Bahasa dan Sastra Universitas AKI

Makkulau, F.W. 2008. Manusia Bissu, Makassar: Pustaka Refleksi.

Mujahiduddin. 2004. Konsep Calabai dalam Pandangan Komunitas Bissu di Pangkep Sulawesi Selatan (Sebuah Kajian Fenomenologi Edmund Husserl), Tesis: Fakultas Filsafat UGM.

Pelras, C. 1996. The Bugis, New York: Blackwell Publishers.

Syahrul. 2013. Menjadi Muslim Yang Animis; Telaah Identitas Bissu Segeri Di Kabupaten Pangkep, dalam Al-Fikr Volume 17 Nomor 3 Tahun 2013.

Syamsuddin. 2010. Studi Fenomenologi Dinamika Psikologi Peran Gender Bissu, Tesis: Fakultas Psikologi UGM.

Syahrir, N. 1993. Sere Bissu; Sebuah Ritual Adat Masyarakat Segeri Mandalle Sulawesi Selatan, Fungsinya Dahulu dan Kini, Tesis: Program Pengkajian Seni Pertunjukan Jurusan Ilmu-ilmu Humaniora UGM.

Trianto, Medi. 2003. Di Sini Ia Terhormat dalam http ://wap. Indosiar. com, diakses 7 Juli 2018).

Yauri, A.M. 2008. Bissu Gaul: Reinvensi Budaya Kelompok Bissu di Kabupaten Wajo Sulawesi Selatan dalam Agama dan Kearifan Lokal dalam Tantangan Global, Editor Irwan Abdullah, Ibnu Mujib. M. Iqbal Ahnaf, Yogyakarta: Pustaka Pelajar. 